\title{
Correlation Among the Input Thermal Parameters and Thermography Measurements Data of the Resistance Seam Welding
}

\author{
Vinicius Santos de Deus ${ }^{a, b}$ (D), Jose Adilson Castro ${ }^{a^{*}}$ (D), Sandro Rosa Correa ${ }^{c}$ \\ ${ }^{a}$ Universidade Federal Fluminense (UFF), Programa de Pós-Graduação em Engenharia Metalúrgica \\ (PPGEM), Volta Redonda, RJ, Brasil \\ ${ }^{b}$ Companhia Siderúrgica Nacional (CSN), Gerência Geral de Folhas Metálicas (GGFM), \\ Volta Redonda, RJ, Brasil \\ ${ }^{c}$ Companhia Siderúrgica Nacional (CSN), Gerência Geral de Pesquisa e Desenvolvimento, \\ Volta Redonda, RJ, Brasil
}

Received: January 21, 2020; Accepted: February 17, 2020

\begin{abstract}
Resistance Seam Welding (RSEW) is commonly used in continuous steel processing for joining steel coils. Experimental studies focused on the welding process quality controls are justified by their wide application and influence on the performance of steelmaking processes. The present study focuses on the continuous annealing line welding process using as sample, a low carbon steel $(0.07 \% \mathrm{C})$ with $0.21 \mathrm{~mm}$ thickness. The work proposes a correlation of thermal input, electric current parameter and thermogram monitoring during RSEW procedures. A methodology was developed to determine the real thermal profiles values by means of association of the thermograms with the sample emissivity curve. Three heat input levels were used, $3.64 \mathrm{~J}_{\mathrm{mm}} \mathrm{m}^{-1}, 5.09 \mathrm{~J} . \mathrm{mm}^{-1}$, and $6.38 \mathrm{~J} . \mathrm{mm}^{-1}$, respectively, for typical C-Mn steel. The thermal welding profile obtained experimentally exhibited linear correlation coefficients $(R)$ of 0.99 with the electric current welding parameter and $(R)$ of 0.99 with the calculated thermal input, respectively. The welds metallurgical characterizations results, expressed through the ductility and welds nuggets analysis, were conducted to correlate the welds quality with the welding thermal input. The Erichsen cupping test showed that the higher the thermal input corresponds to higher ductility of the welds. Nevertheless, the heat input of $5.09 \mathrm{~J} . \mathrm{mm}^{-1}$ indicated better-balanced properties: ductility, weld nugget discontinuity, nugget size, and no expulsion of the melt material.
\end{abstract}

Keywords: Resistance seam welding, thermography, thermal input, metallurgical characterization, emissivity curve

\section{Introduction}

In the steelmaking processes, especially the rolling mill and finishing sectors, Resistance Seam Welding (RSEW) is commonly employed to join steel coils with thickness up to $3 \mathrm{~mm}$. The heat required to form the weld joint is provided by the resistance to the electric current to pass through the parts being joined. Under the most common welding conditions, the quality of the weld joints depends on the heat distributions responsible for forming the melting and heat affected zones in the base material. The Joule effect is responsible for heating the base material meanwhile, the material heat conduction, radiation, and convection are the main drivers for cooling ${ }^{1}$. The electric current is transmitted by two rotating electrodes arranged vertically aligned and in contact with the sides of the opposing sheets to be welded. In this step, the necessary pressure is exerted for proper contact between the base materials and the electrodes rotate with constant speed over the materials, overlapping to perform a continuous joint, characteristic of the seam welding.

The heat input associated with this welding process can be expressed using Equation 1, where " $H$ " is the heat input,

*e-mail: joseadilsoncastro@id.uff.br
" $U$," the electric welding voltage, " $I$," the electric welding current, " $\Delta t$," the welding time and " $v$," the welding speed ${ }^{2}$.

$$
H=\frac{1}{(v \times \Delta t)} \int_{0}^{\Delta t}(U I) d t
$$

The welding joint quality is adequated when the welding zones are free of metallurgical discontinuities such as surface cracks, lack of fusion at the interface or material expulsion from the weld nugget. Non-destructive essays (NDE) are suitable to assure the quality of the welding regions and guaranty the metallurgical properties continuity ${ }^{3}$. The thermography technique was selected from among the existing NDE due to its characteristics of non-contact with the material and, therefore, does not interfere in the welding processing procedure thus having potential for it's application in online data acquisition ${ }^{4,5}$. The accuracy of the thermography technique, however, is strongly dependent on the emissivity of the material. Moreover, the emissivity of the materials depends on the surface roughness, impurities, surface oxidation, coatings and temperature. The emissivity found in the literature for the C-Mn steels may not be accurate enough for the actual welding conditions in the 
RSEW process of the continuous annealing unity. Thus, estimated values of emissivity are usually adopted due to lack of reliable experimental results ${ }^{6-9}$. Most of the research that used the thermography in the evaluation of welding was based on constant values of emissivity, as in the works of Valiorgue et al. ${ }^{9}$ and Chen and Feng ${ }^{5}$. These previous results did not work with actual temperature values due to the lack of knowledge of emissivity variations during the welding process. Applying the actual emissivity values in thermographic analysis is important because each material type has a different emissivity dynamic variation as a function of its temperature. The knowledge of the material emissivity response (emissivity curve) is fundamental to guarantee the accuracy of a thermographic analysis. Due to the uncertainty regarding the emissivity curve of the material evaluated under its specific conditions of roughness, impurities and oxidation during temperature rise, we propose, in this research, a method to evaluate an emissivity curve as a function of temperature evolution and its subsequent use for the correction of temperature values acquisition from the thermographic camera. Even with the wide use of RSEW in the steelmaking processes and the importance of weld quality in these processes performance, the number of papers registered in the scientific databases associated to the subject of RSEW is reduced when compared to other resistance welding processes. Usually, most of the discussions and conclusions valid for the Resistance Spot Welding (RSW) are extended to analyze the RSEW processes ${ }^{10}$. This research thus meets this demand for studies involving a better understanding of the phenomena associated with the RSEW process and focus on the RSEW process of the continuous annealing production line, where the steel is received is in the state of hardening from the previous cold rolling mill process within the sheet metal manufacturing flowsheet. The material is a low carbon steel $(0.07 \% \mathrm{C})$ with $0.21 \mathrm{~mm}$ thickness. Subsequently, we propose methodologies to correlate the welding thermography profile with monitored welding parameters acquisition in the online industrial process. Therefore, it is useful for monitor the online quality of the welding and assures the properties of the heat affected zone (HAZ).

The innovation of this study comes from the lack of investigation correlating the resistance seam welding parameters with the thermal profiles and mechanical properties of low carbon steel during its welding on productive flow in the continuous annealing process lines. This work furnishes an experimental approach, which is necessary for the future development of a system able to the real-time prediction using online thermography monitoring assessment of weld quality in the studied process. We propose methodologies to correlate the welding thermography profile with monitored welding parameters in the online industrial process acquisition data. Therefore, it is useful for monitoring the online quality of the welding and assures the necessary properties of the heat affected zone (HAZ).
The innovative aspect of this research relies in covering the lack of studies for obtaining correlation of the resistance seam welding parameters with the thermal profiles developed during the industrial procedure and their impacts on the mechanical properties of low carbon steel during its welding on productive flow in the continuous annealing process lines. Therefore, we enlight two important feature of this study that clearly show the improvement on the field compared with the actual literature: i) a method for obtaining the fundamental data for the online correct measurement of the temperature distribution in the process, emissivity of the carbon steel and ii) good correlations equations for the prediction of important welding parameters using primary data of the process such as welding current and voltage. These two important features of these research are fundamental for ensuring high productivity and efficiency of the industrial process accompanied by welding quality.

\section{Methods}

\subsection{Material}

Samples of $0.21 \mathrm{~mm}$ thickness and $856 \mathrm{~mm}$ wide of steel plate were taken from a selected representative coil in the productive stock of the continuous annealing line at CSN, Brazil. It is low carbon steel which has been subjected to $89 \%$ reduction in the pre-cold rolling process, with the composition presented in Table 1.

\subsection{Experimental weldings and data acquisition}

The samples of steel plates were submitted to experimental welding on the Taylor-Winfield, $150 \mathrm{KVA}, 60 \mathrm{~Hz}, 440 \mathrm{Vac} / 11 \mathrm{Vac}$ seam welding machine. The pressure and velocity parameters were kept constant, and the welding current varied to obtain three different welding levels of heat input. The material overlap adjustment was $4.5 \mathrm{~mm}$, and the continuous welding mode was used in the experiment. Welding discs with a flat surface of $8.5 \mathrm{~mm}$ width were used, and the weld samples were enumerated and classified according to the level of the heat input, Table 2.

Using automation and instrumentation adapted in the welding machine (programmable logic controller, frequency inverter, human-machine interface, sensors, transducers, and oscilloscope) the welding variables were recorded at a sampling rate of 0.2 measurements per second. The following variables were stored: welding electric current effective value, the pressure between welding electrodes, welding speed, and electric voltage effective value.

The thermography was used to record the experimental welding temperature profiles by adapting the Flir thermographic camera, model T440, resolution $240 \times 320$ pixels integrated to the software Flir Tool+. Figure 1 illustrates the adaptation of the thermography equipment and data system acquisition in the industrial welding machine.

Table 1. Sample chemical composition (analysis).

\begin{tabular}{ccccccccc}
\hline \multicolumn{10}{c}{ Chemical Composition (\%) } \\
\hline $\mathbf{C}$ & $\mathbf{M n}$ & $\mathbf{P}$ & $\mathbf{S}$ & $\mathbf{S i}$ & $\mathbf{C u}$ & $\mathbf{N i}$ & $\mathbf{C r}$ & $\mathbf{A l}$ \\
\hline 0.074 & 0.333 & 0.013 & 0.010 & 0.003 & 0.009 & 0.007 & 0.010 & 0.027 \\
\hline
\end{tabular}


Table 2. Experimental planningccovering the important factors.

\begin{tabular}{cc}
\hline Welds identification & $\begin{array}{c}\text { Heat input levels (adjusted } \\
\text { by welding current) }\end{array}$ \\
\hline 1 & low \\
\hline 2 & medium \\
\hline 3 & high \\
\hline
\end{tabular}

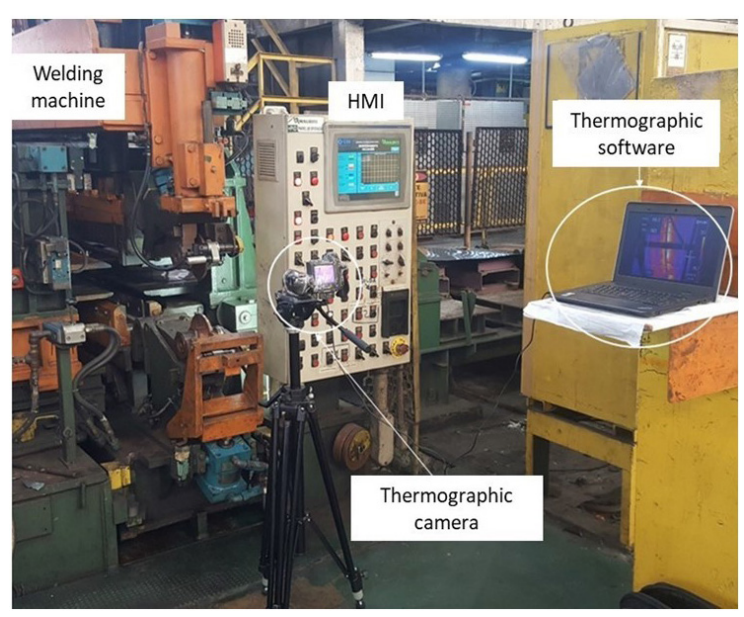

Figure 1. Adaptation of equipment for recording the welding parameters and thermographic data.

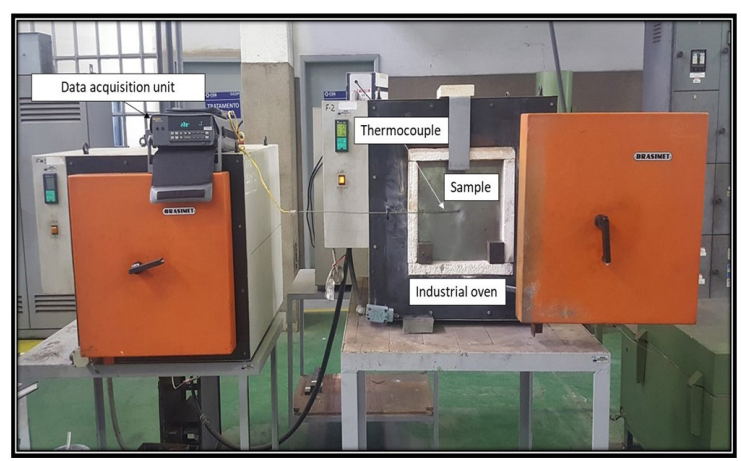

Figure 2. Preparation of equipment and instrumentation for the material emissivity test.

\subsection{Material emissivity curve determination}

The emissivity knowledge of the material submitted to the welding process is a condition for the correct parametrization of the thermal image analysis software. The material base emissivity curve was determined by laboratory experiments carried out in a Brasimet, $1300^{\circ} \mathrm{C}$, industrial oven. A $350 \times 350 \mathrm{~mm}^{2}$ sample was cut, and a $\mathrm{K}$-type thermocouple was attached at its center. The oven door was kept open, and the sample was strategically placed in its opening, as shown in Figure 2.

The emissivity curve was determined by simultaneously comparing the temperature values obtained through the thermocouple fixed in the sample and the thermograms recorded by the thermographic camera. Temperature information records were performed every $50^{\circ} \mathrm{C}$ from $100^{\circ} \mathrm{C}$ to $800^{\circ} \mathrm{C}$. The emissivity values for each temperature (emissivity curve) were determined by adjusting and recording the emissivity parameter in the thermography software to match the thermogram temperature with the actual thermocouple temperature taken as a reference.

In the thermograms analysis, maximum, minimum, and average temperature values were considered within an area of 1771 monitored points resolution (Figure 3). In this way, the maximum, average, and minimum emissivity curves could be determined.

\subsection{Welding thermal profile adjustment through the emissivity curve}

The previous recorded welding thermal profiles were adjusted through the average emissivity curve obtained in the experiment. For all thermal profile analyzed points at a $0.2 \mathrm{~s}$ sampling interval throught thermogram software, the temperature values were adjusted by the emissivity parameter extracted from the emissivity curve obtained in the procedure of item 2.3 .

\subsection{Metallurgical Characterization}

To ensure the adequate mechanical properties of the analyzed weldments, the cupping test was performed on an Erichsen model 134 equipment. Five tests were performed

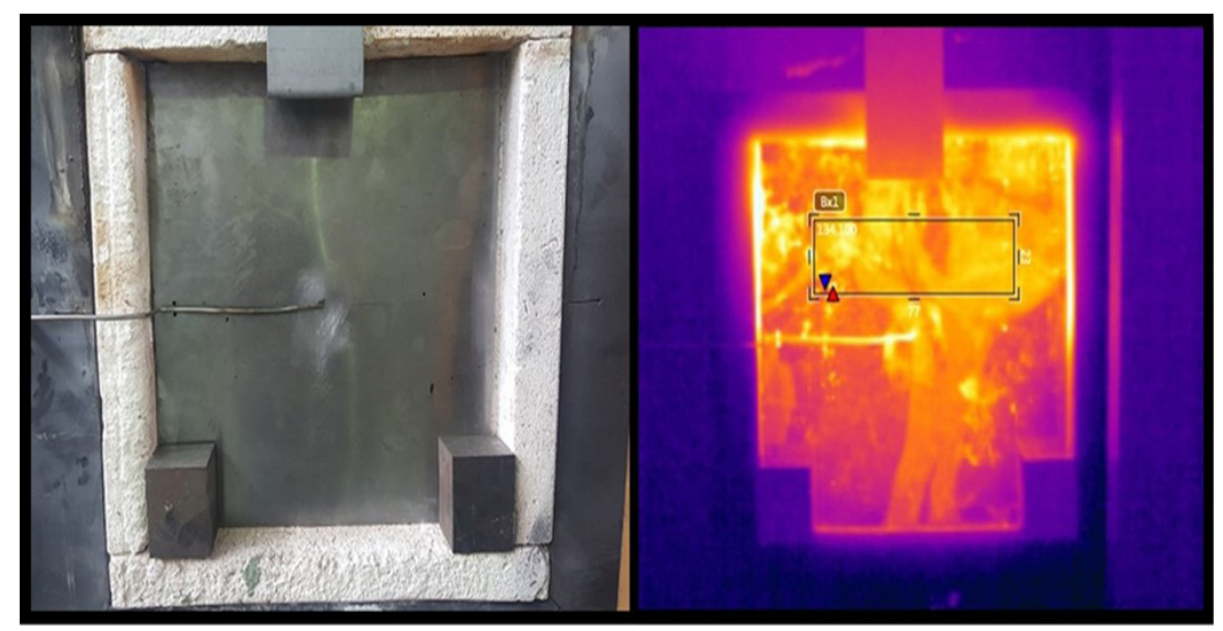

Figure 3. Thermograms analysis with 1771 pixels monitored area view. 
on each weld sample, and they were evenly distributed along the weld seam according to Figure 4.

The metallographic analysis was performed using a Carl Zeiss optical microscope, model Axio Imager.M2m integrated to the AxioVision SE64 software. Samples were prepared by conventional polishing and attack with Nital $3 \%$ to allow macrography images and analysis.

\section{Results and Discussion}

\subsection{Emissivity curve}

Figure 5 summarizes the emissivity test results of the base material. It can be verified the existence of a range in the emissivity curve represented by the maximum and minimum emissivity curves obtained, which is explained due to the nonuniformity of oil residues distribution in the sample, usually inherent in the online acquisition data in the steelmaking process.

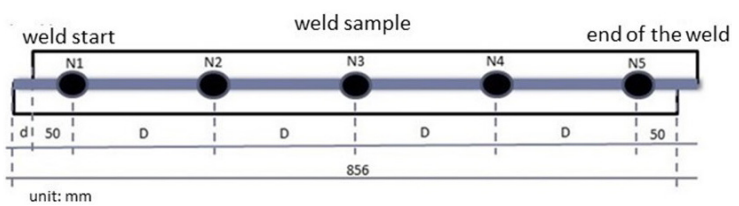

Figure 4. Schematic sampling location of the Erichsen cupping test in the weld fillet.

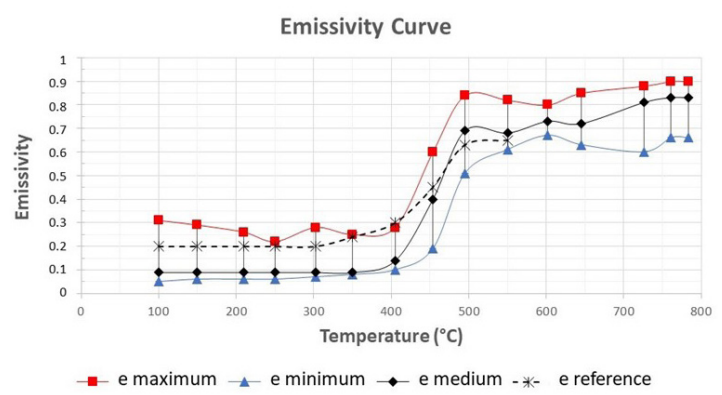

Figure 5. Experimental emissivity curve measured in this study for the $\mathrm{C}-\mathrm{Mn}$ material and comparison with literature data of similar material (dot line).

\section{Thermal profiles (constante emissivity)}

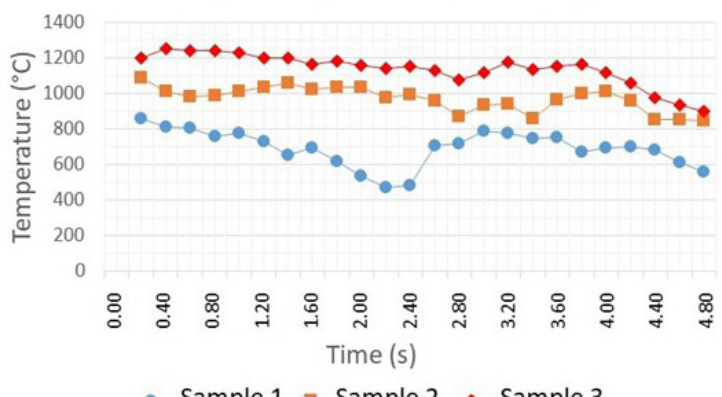

$\bullet$ Sample 1 - Sample $2 \multimap$ Sample 3
Previous results presented in the literature that analyzed the steel emissivity using other methodologies and lower temperature interval presents results within the range of the measured values obtained in this work, which can be compared for the same temperature interval ${ }^{11,12}$. Paloposki and Liedquist ${ }^{12}$ analyzed a $1.5 \mathrm{~mm}$ thickness cold-rolled low carbon steel at a temperature of $150^{\circ} \mathrm{C}$ to $550^{\circ} \mathrm{C}$ and its emissivity curve (e reference - dot line) was also represented in Figure 5, where it is possible to observe that the authors measurements are in the range of the present results, which indicated the adequacy of the measurement methodology we proposed.

In general, the emissivity value is lower in polished surfaces and higher in oxidized surfaces, being dependent on its chemical composition, internal structure and strongly affected by surface conditions ${ }^{11}$. In the present experiment, the sample darkening (burning of the oil cover and oxidation) was observed from the temperature around to $400^{\circ} \mathrm{C}$, which justifies the sharp increase of the emissivity from these temperature levels.

\subsection{Thermal profile adjustment through the emissivity curve}

The three experimental welding thermal profiles were recorded, and Figure 6 shows the comparison of the thermal profiles based on a constant initial emissivity $(\mathrm{e}=0.27)$ with the thermal profiles corrected by the medium emissivity curve. It can be observed the discrepancy of the thermal profiles from the reference temperature.

\subsection{Correlation among the welding parameters and the welding thermal profiles}

For a better understanding of the correlations of the variables in the welding process, the recorded instantaneous values of the welding parameters were arranged in a database synchronized in time with the thermal profiles obtained with the thermography. Figures 7 show the representative welding variables in the performed experiment for the experimental run 1 .

Table 3 shows the welding experimental data of parameters and variables acquired, from which the welding heat input values were calculated.

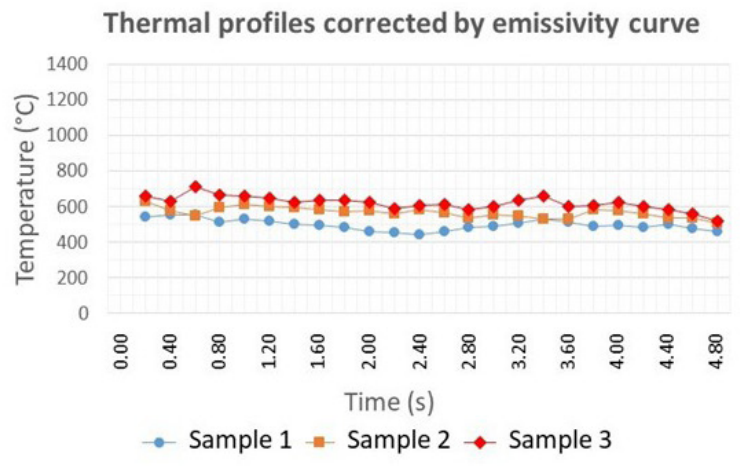

b) After

Figure 6. Comparison between the welding thermal profiles before and after the emissivity correction. 
The electric current parameter, the calculated heat input, and measured thermographic profile presented a strong correlation and Figure 8 shows the graphical correlations among these variables. It can be observed that the measured thermographic welding profile with emissivity curve correction exhibited excellent linear correlation coefficients $(R)$ of 0.9995 with the electric current and (R) of 0.9990 with the thermal input, respectively. These results enable the use of thermographic data to confirm the weld joint quality based on thermal input and electric current parameter.

\subsection{Metallurgical characterization}

The Erichsen cupping test results are organized in Table 4. By comparing the mean values of deformation up to the samples rupture, it was verified that the higher the welding thermal input, the more ductile the welds were.
This observation can be explained by the relation between the thermal input and the recrystallization of the material obtained during welding, which is a determinant of the ductility of the material coming from the welding ${ }^{13}$.

Figure 9 shows the metallographic analysis of the cross-sections of the seam welds central region. Some details can be observed by exploring the welding heat input intensity effect on the weld nuggets. Figure 9 shows that $3.64 \mathrm{~J}_{\mathrm{mm}} \mathrm{m}^{-1}$ resulted in the smallest weld nugget with a higher amount of discontinuities in the weld interface. The $6.38 \mathrm{~J} . \mathrm{mm}^{-1}$ heat input, despite having resulted in a larger weld nugget, presented some void defects and projections of the molten material from the weld nugget. The $5.09 \mathrm{~J} . \mathrm{mm}^{-1}$ heat input resulted in the intermediate dimension weld nugget and fewer discontinuities at the weld interface. Similarly, studies related to the weld analysis confirm the degradation of the

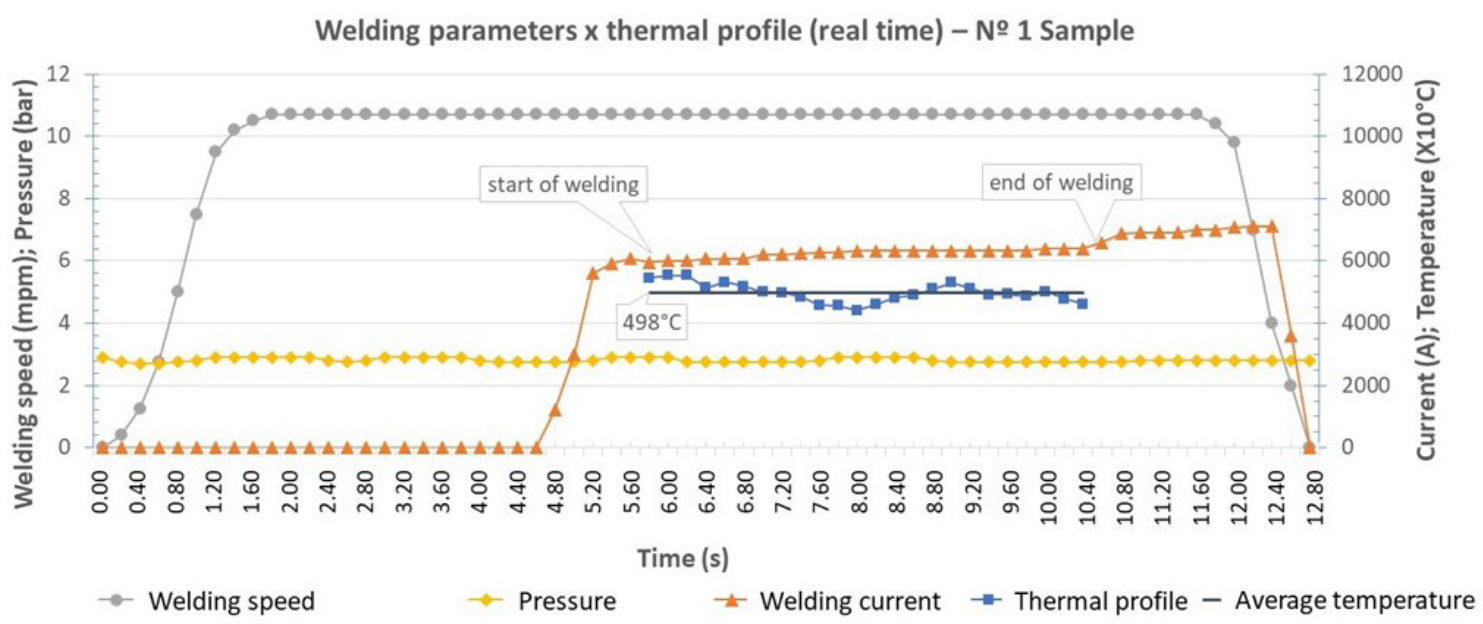

Figure 7. Monitoring of the welding parameters for the experimental run number 1.

Table 3. Welding experimental data.

\begin{tabular}{|c|c|c|c|c|c|c|c|}
\hline \multirow[b]{2}{*}{ Sample } & \multicolumn{2}{|c|}{ Welding Variables (monitored) } & \multicolumn{3}{|c|}{ Welding Parameters (acquisition) } & \multirow{2}{*}{$\begin{array}{c}\text { NDT } \\
\text { Temperature } \\
\left({ }^{\circ} \mathrm{C}\right)\end{array}$} & \multirow{2}{*}{$\begin{array}{c}\text { Predicted } \\
\text { Calculated heat } \\
\text { input }(\mathrm{J} / \mathrm{mm})\end{array}$} \\
\hline & $\begin{array}{l}\text { Welding time } \\
\text { (s) }\end{array}$ & $\begin{array}{l}\text { Voltage rms } \\
\text { (V) }\end{array}$ & $\begin{array}{l}\text { Current rms } \\
\text { (A) }\end{array}$ & $\begin{array}{l}\text { Welding speed } \\
(\mathrm{mpm})\end{array}$ & $\begin{array}{c}\text { Welding } \\
\text { pressure (bar) }\end{array}$ & & \\
\hline 1 & 4.76 & $0.104+/-0$ & $6242+/-132$ & $10.7+/-0$ & $2.8+/-0.1$ & $498+/-30$ & $3.64+/-0.08$ \\
\hline 2 & 4.78 & $18+/-0$ & $7698+/-135$ & $10.7+/-0$ & $2.8+/-0.1$ & $568+/-29$ & $5.09+/-0.09$ \\
\hline 3 & 4.73 & $0.131+/-0$ & $8687+/-139$ & $10.7+/-0$ & $2.8+/-0.1$ & $621+/-38$ & $6.38+/-0.10$ \\
\hline
\end{tabular}

Correlation coefficient $\mathrm{R}=0.9971$

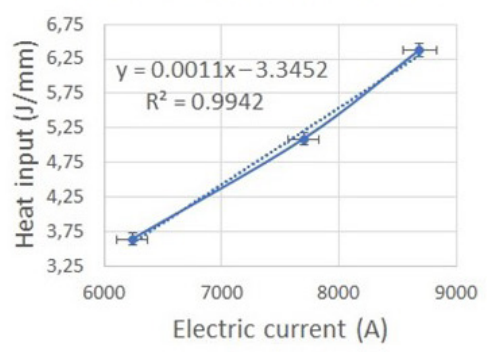

a)
Correlation coefficient $\mathrm{R}=\mathbf{0 . 9 9 9 0}$

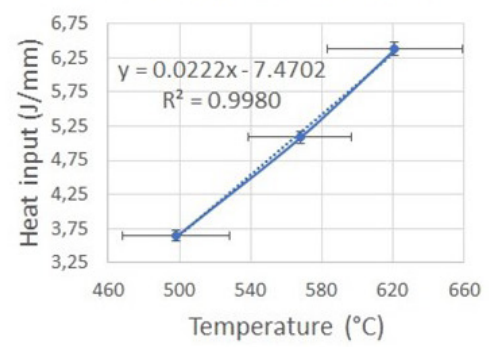

b)

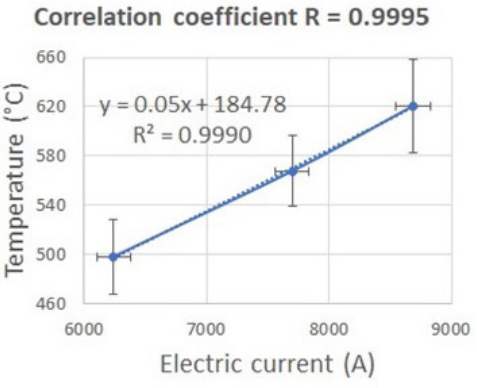

c)

Figure 8. Graphical correlation among welding variables (electric current parameter, calculated thermal input and monitored thermal profile). 
Table 4. Results of the Erichsen cupping test.

\begin{tabular}{|c|c|c|c|c|c|c|c|c|}
\hline \multirow[b]{2}{*}{ Sample } & \multicolumn{7}{|c|}{ Deformation (mm) } & \multirow{2}{*}{$\begin{array}{l}\text { Deformation ratio } \\
\text { Sample/base metal }\end{array}$} \\
\hline & N1 & $\mathbf{N 2}$ & N3 & N4 & N5 & Average & $\begin{array}{l}\text { Standard } \\
\text { deviation }\end{array}$ & \\
\hline Base metal & 2.78 & 2.83 & 2.78 & 2.73 & 2.73 & 2.77 & 0.037 & 1 \\
\hline 3.64 J.mm- $\mathrm{mm}^{-1}$ & 1.88 & 1.88 & 1.83 & 1.83 & 2.03 & 1.89 & 0.073 & 0.68 \\
\hline 5.09 J.mm $^{-1}$ & 2.18 & 2.18 & 2.48 & 2.38 & 2.48 & 2.34 & 0.136 & 0.84 \\
\hline 6.38 J.mm-1 & 2.23 & 3.08 & 3.08 & 2.38 & 2.88 & 2.73 & 0.358 & 0.98 \\
\hline
\end{tabular}

Table 5. Weld nuggets dimensional characterization.

\begin{tabular}{|c|c|c|c|c|c|c|}
\hline \multirow[b]{2}{*}{$\begin{array}{l}\text { Heat input } \\
\left(\mathrm{J} . \mathrm{mm}^{-1}\right)\end{array}$} & \multirow[b]{2}{*}{ Characterization } & \multicolumn{5}{|c|}{ Weld cross section dimensional (mm) } \\
\hline & & Seam weld start & $\begin{array}{l}\text { Seam weld } \\
\text { middle }\end{array}$ & Seam weld end & Average & $\begin{array}{l}\text { Standard } \\
\text { deviation }\end{array}$ \\
\hline \multirow{3}{*}{3.64} & Overlap & 4.49 & 4.53 & 4.56 & 4.53 & 0.03 \\
\hline & Weld nugget length & 2.29 & 3.21 & 3.26 & 2.92 & 0.45 \\
\hline & Weld nugget height & 0.38 & 0.30 & 0.35 & 0.34 & 0.03 \\
\hline \multirow{3}{*}{5.09} & Overlap & 4.53 & 4.46 & 4.44 & 4.48 & 0.04 \\
\hline & Weld nugget length & 3.49 & 3.59 & 3.70 & 3.59 & 0.09 \\
\hline & Weld nugget height & 0.36 & 0.38 & 0.35 & 0.36 & 0.01 \\
\hline \multirow{3}{*}{6.38} & Overlap & 4.64 & 4.75 & 4.85 & 4.75 & 0.09 \\
\hline & Weld nugget length & 3.38 & 3.91 & 3.84 & 3.71 & 0.24 \\
\hline & Weld nugget height & 0.38 & 0.38 & 0.32 & 0.36 & 0.09 \\
\hline
\end{tabular}
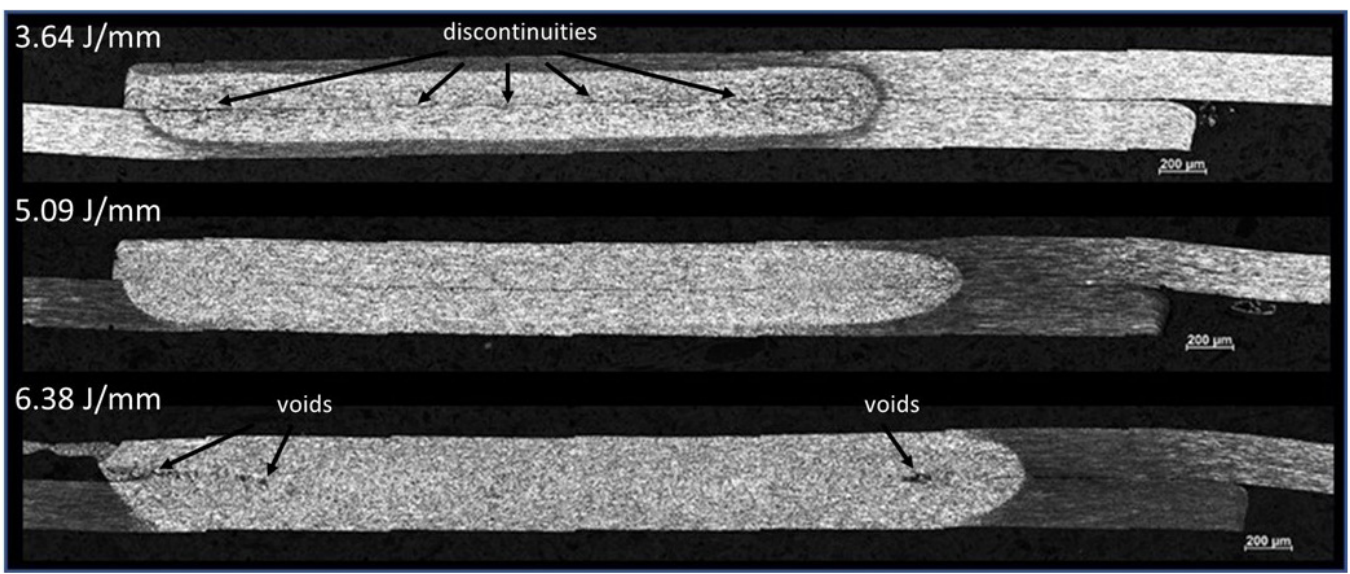

Figure 9. Comparison of the microstructure of the three levels of the heat input analyzed weld nuggets. Nital 3\%. Magnification $100 \mathrm{X}$.

weld quality due to the excessive local heat input ${ }^{14}$. These results emphasize the importance of the strict control of the thermal profile during the continuous welding of the steel sheets. Considering the permissible range for the welding thermal input, it is assumed that the ideal range has the upper limit, the condition where the phenomenon of molten material expulsion begins and the lower limit, the condition where the low thermal input does not guarantee a continuous joint in the weld interface ${ }^{1}$. Based on our results, the $5.09 \mathrm{~J} . \mathrm{mm}^{-1}$ heat input presented the best weld nugget quality among the three levels, presenting the best balance between the non-expulsion of melting the material and the continuity at the weld interface. Therefore, this procedure is recommended.

The weld nuggets dimensional was characterized, as shown in Table 5. It was observed that the weld nuggets length increase and their height decrease in the longitudinal extension of each weld. The weld nugget height longitudinal decrease is most evident in the heat input of $6.38 \mathrm{~J}_{\mathrm{mm}} \mathrm{mm}^{-1}$. These results can be explained by the tendency to increase the material expulsion by the excessive local temperature during the weld seam longitudinal formation ${ }^{15}$.

\section{Conclusions}

This paper attests to the efficiency of the developed methodologies to:

- $\quad$ online registration of the resistance seam welding thermographic profile;

- determination of the sample emissivity curve;

- correction of thermographic profiles with the emissivity curve.

The results of the metallurgical characterizations of the welds were well correlated with the thermal input welding. The heat input was the determining factor of the weld properties. Based on the obtained results, it was possible to conclude: 
- The material emissivity variation strongly influences the thermal welding profile, and the quality of the thermographic data and the knowledge of the emissivity curve is essential for the correction of the obtained thermographic data;

- The thermal welding profile obtained experimentally exhibited excellent linear correlation coefficients (R) of 0.9995 with the electric current welding parameter and $(\mathrm{R})$ of 0.9990 with the calculated thermal input, respectively;

- The welds metallurgical characterizations results, expressed through the ductility and welds nuggets analysis could be correlated to the welding thermal input, reinforcing its influence on the welds metallurgical properties. The Erichsen cupping test showed that the higher the thermal input corresponds to higher ductility of the welds. Nevertheless, the heat input of $5.09 \mathrm{~J} . \mathrm{mm}-1$ indicated better-balanced properties: ductility, weld nugget discontinuity, nugget size, and no expulsion of the melt material;

The contribution of this work meets the studies in the evaluation of real time welding through END techniques and correlation analysis between welding parameters, thermographic analysis and welds metallurgical characterization. The presented results also contribute to studies focused on the development of systems for weld quality prediction and real time weld quality evaluation.

\section{References}

1. Mira-Aguiar T, Leitão C, Rodrigues DM. Solid-state resistance seam welding of galvanized steel. Int J Adv Manuf Technol. 2016;86:1385-91.

2. Marques PV, Modenesi PJ. Algumas equações úteis em soldagem. Soldag Insp. 2014;19(1):91-101.

3. Nunes RM, Alia BL, Alley RL, Apblett WR Jr, Baeslack WA 3rd. Welding, brazing and soldering. Vol. 6. USA: ASM International; 1993.

4. Broberg P, Sjödahl M, Runnemalm A. Comparison of NDTmethods for automatic inspection of weld defects. Int J Mater Prod Technol. 2015;50(1):1.
5. Chen J, Feng Z. IR-based spot weld NDT in automotive applications. In: Thermosense: Thermal Infrared Applications XXXVII; 2015; Baltimore. Proceedings. Bellingham: SPIE Commercial + Scientific Sensing and Imaging; 2015. Vol. 9485, p. 948513-1-948513-6.

6. Perin AL. Desenvolvimento de um equipamento para medição de emissividade [dissertação]. Porto Alegre: Universidade Federal do Rio Grande do Sul; 2009.

7. Boillot JP, Cielo P, Begin G, Michel C, Lessard M, Fafard $\mathrm{P}$, et al. Adaptive welding by fiber optic thermographic sensing: an analysis of thermal and instrumental considerations. Welding Research Supplement. 1985;209-s-218-s.

8. Mira-Aguiar T, Galvão I, Leitão C, Rodrigues DM. Analysis of weld defects in similar and dissimilar resistance seam welding of aluminium, zinc and galvanised steel. Sci Technol Weld Join. 2015;20(5):409-17.

9. Valiorgue F, Brosse A, Naisson P, Rech J, Hamdi H, Bergheau JM. Emissivity calibration for temperatures measurement using thermography in the context of machining. Appl Therm Eng. 2013;58(1-2):321-6.

10. Maziar J, Esmaiil G, Domiri G, Hasan B, Soheil S, Geraili $\mathrm{N}$, et al. Effect of temperature-dependency of surface emissivity on heat transfer using the parameterized perturbation method. Therm Sci. 2011;15(Suppl. 1):123-5.

11. Richmond JC, Harrison WN. Total hemispherical emittance of coated and uncoated inconel and types 321 and 430 stainless steel. J Res Natl Bur Stand, Sect C, Eng Instrum. 1962;66C(3):261-9.

12. Paloposki T, Liedquist L. Steel emissivity at high temperatures: VTT Research Notes. Finland: VTT Technical Research Centre of Finland; 2005. p. 1-81. Report No.: 2229 [cited 2020 Feb 17]. Available from: https://www.osti.gov/etdeweb/biblio/20712093

13. Deus VS. Correlação do aporte térmico e parâmetros de processo de soldagem a resistência elétrica com perfis térmicos obtidos através de termografia [dissertação]. Niterói: Universidade Federal Fluminense; 2019.

14. Palacíos AMG. Uso de técnicas de termografia para detecção de descontinuidades no processo GTAW através do monitoramento da poça de fusão [dissertação]. Brasília: Universidade de Brasília; 2010.

15. Deus VS, Corrêa SR, Castro JA. Correlação do aporte térmico com os parâmetros do processo de soldagem por costura aplicada em aço baixo carbono. In: $73^{\circ}$ Congresso Anual da ABM; 2018; São Paulo. Proceedings. São Paulo: ABM; 2018. p. $338-48$. 